\title{
HUBUNGAN ANTARA DUKUNGAN KELUARGA DENGAN MOTIVASI MOBILISASI DINI PADA IBU POST SEKSIO SESAREA DI RSUD 45 KUNINGAN
}

\author{
${ }^{1}$ Anggit Kartikasari, ${ }^{2}$ Mala Tri Marliana, ${ }^{3}$ Nira Purwita Sari \\ Sekolah Tinggi Ilmu Kesehatan Kuningan
}

anggit8616@gmail.com

\begin{abstract}
Abstrak
Pergerakan yang dilakukan ibu sedini mungkin setelah melahirkan baik secara normal maupun seksio sesarea disebut juga mobilisasi dini. Manfaat mobilisasi diantaranya merasa lebih sehat dan kuat, faal usus dan kandung kencing lebih baik, mengajarkan untuk merawat anaknya, Tidak menyebabkan perdarahan yang abnormal. Perilaku kesehatan ini dipengaruhi oleh motivasi ibu post seksio sesarea baik dari intrinsik maupun ekstrinsik Tujuan penelitian ini untuk mengidentifikasi hubungan antara dukungan keluarga dengan motivasi mobilisasi dini pada ibu post seksio sesarea. Jenis penelitian analitik rancangan korelasional, populasi dalam penelitian ini ibu post seksio sesarea. Teknik pengambilan sampling menggunakan purposive sampling. Instrumen yang digunakan berupa kuesioner. Analisis data yang digunakan dalam penelitian ini adalah analisis univariat dan bivariat analisis univariat menghasilkan distribusi dan persentase dari tiap variabel, sedangkan analisis bivariat menggunakan uji Spearman Rank. Hasil analisis univariat sebagian besar ibu post seksio sesarea mendapatkan dukungan keluarga baik 60\%, dan motivasi mobilisasi dini 66,7\%. Hasil analisis bivariat didapatkan ada hubungan antara dukungan keluarga dengan motivasi mobilisasi dini nilai $\mathrm{p}(0,004)$. Disarankan ibu post seksio sesarea tetap termotivasi untuk melaksanakan mobilisasi dini dan mengikutsertakan keluarga untuk membantu dalam melakukan mobilisasi bertahap mulai dari miring kanan-miring kiri, duduk dan berjalan.
\end{abstract}

Kata Kunci : Dukungan keluarga, motivasi mobilisasi dini

\section{Pendahuluan}

Mobilisasi dini merupakan pergerakan yang dilakukan ibu sedini mungkin setelah melahirkan. Mobilisasi yang dilakukan secara bertahap sangat berguna untuk membantu jalannya 
JOURNAL OF MIDWIFERY CARE:

VOL. 01 NO. 02, JUNI 2021

DOI: $10.34305 / \mathrm{jmc} . v 1 \mathrm{i02} .257$
Ciptaan disebarluaskan di bawah

Lisensi Creative Commons Atribusi-

NonKomersial-BerbagiSerupa 4.0

Internasional. penyembuhan pasien. Secara psikologis mobilisasi akan memberikan kepercayaan pada pasien bahwa dia mulai merasa sembuh. Perilaku kesehatan ini dipengaruhi oleh motivasi ibu post seksio sesarea baik dari intrinsik maupun ekstrinsik. Sifat malas akan muncul diakibatkan karena Kurangnya dukungan ibu nifas untuk melakukan mobilisasi dini, bahkan enggan atau tidak berkehendak untuk melakukan mobilisasi dini. Terdapatnya ibu post seksio sesarea yang tidak mau melakukan mobilisasi dini dikaitkan dengan motivasi yang rendah. Oleh karena itu untuk meningkatkan motivasi ibu salah satunya dengan dukungan keluarga yang diberikan kepada ibu post seksio sesarea.

Keluarga merupakan salah satu faktor yang berperan penting dalam mobilisasi dini pasien, mobilisasi dini merupakan mitra bagi perawat dalam rangka memberikan perawatan kepada pasien. Kerjasama antara keluarga dan perawat adalah memfasilitasi keluarga untuk berperan aktif dalam asuhan keperawatan pasien dirumah sakit dan memberdayakan kemampuan keluarga baik dari aspek pengetahuan, keterampilan dan sikap dalam melaksanakan perawatan di rumah sakit. Dukungan keluarga sangat penting untuk motivasi pasien dalam menjalankan mobilisasi, akan tetapi masih banyak keluarga yang kurang mengerti bagaimana cara merawat keluarga yang sakit, oleh karena itu peran keluarga sangat perlu sekali dalam rangka untuk memberikan dukungan terhadap pasien, supaya pasien tersebut sembuh dari penyakit dan komplikasi yang mungkin timbul setelah pasca operasi (Zainuddin S, 2002).

Dukungan keluarga diartikan sebagai bantuan yang diberikan oleh anggota keluarga yang lain sehingga akan memberikan kenyamanan fisik dan psikologis pada orang yang dihadapkan pada situasi stress (Taylor, 2006). Dukungan keluarga merupakan informasi verbal atau nonverbal, saran, bantuan yang nyata atau tingkah laku yang diberikan oleh orang-orang yang akrab dengan subjek di dalam lingkungan sosialnya atau yang berupa kehadiran dan hal-hal yang dapat memberikan keuntungan emosional atau berpengaruh pada tingkah laku penerimanya (Zainuddin S, 2002). Terjadi peningkatan suhu tubuh yang dapat mengakibatkan resiko terjadinya infeksi pasien post seksio sesarea, perdarahan abnormal dan subinvolusi uterus merupakan dampak jika pasien tidak 
JOURNAL OF MIDWIFERY CARE:

VOL. 01 NO. 02, JUNI 2021

DOI: $10.34305 / \mathrm{imc} . v 1 \mathrm{i02} .257$
Ciptaan disebarluaskan di bawah

Lisensi Creative Commons Atribusi-

NonKomersial-BerbagiSerupa 4.0

Internasional. melakukan mobilisasi dini diantaranya (Dinar Listiayani, 2014)

Motivasi yang dimiliki oleh seseorang sangat berpengaruh terhadap pelaksanaan mobilisasi dini secara mandiri. Peran dan dukungan keluarga yang diberikan jika tidak diikuti dengan motivasi yang baik membuat ibu akan tetap memiliki ketergantungan kepada petugas kesehatan dan keluarga dalam pelaksanaan mobilisasi dini. Ibu pasca seksio sesarea akan mengalami infeksi pada luka seksio sesarea jika luka tersebut tidak dirawat dengan baik, maka luka tersebut harus dirawat dengan baik agar tidak terjadi. Dengan adanya luka operasi Seringkali ibu membatasi pergerakan tubuhnya, sehingga proses penyembuhan luka dan pengeluaran cairan atau bekuan darah kotor dari rahim ibu akan terpengaruh. Dalam membantu proses penyembuhan luka post sectio caesarea disarankan untuk melakukan mobilisasi dini, tetapi kadang sulit untuk melakukan mobilisasi karena ibu merasa letih dan sakit pada luka operasinya. Oleh karena itu ibu pasca seksio sesarea memerlukan dukungan keluarga untuk membantu pelaksanaan mobilisasi dini lebih maksimal dilakukan.

Berdasarkan penelitian yang dilakukan oleh Amalia (2020) di Ruang
Bedah RSUD Dr. H. Bob Bazar didapatkan hasil bahwa mayoritas keluarga responden memberikan dukungan yang baik yakni dan sebagian besar responden melakukan mobilisasi dini post operasi saat dirawat di rumah sakit. Ada hubungan antara dukungan keluarga dengan pelaksanaan mobilisasi dini pasien post operasi yang dirawat di ruang bedah RSUD Dr. H. Bob Bazar, SKM Kalianda $(\mathrm{p}$ value $=0,003)$ dan OR 4,48. Penelitian yang sejalan juga diteliti oleh Ermanto, (2019) yang dilakukan di Rumah Sakit Anna Medika Bekasi, dengan hasil penelitian menunjukkan bahwa adanya hubungan pengetahuan dan dukungan suami dengan pelaksanaan mobilisasi dini.

Latihan mobilisasi dini yang dilakukan oleh pasien post operasi memerlukan peranan dan dukungan dari keluarga pasien. Keluarga bertanggung jawab atas setiap aspek perawatan kesehatan anggota keluarga. keberhasilan dan kegagalan upaya pemulihan pasien sangat tergantung dari peran serta keluarga. Orang yang hidup dalam lingkungan yang saling mendukung, akan jauh lebih baik kondisinya dari mereka yang tidak memiliki dukungan ini, karena dengan dukungan akan dapat memperkecil terjadinya dampak stress dan secara langsung dapat 
JOURNAL OF MIDWIFERY CARE:

VOL. 01 NO. 02, JUNI 2021

DOI: $10.34305 / \mathrm{imc} . v 1 \mathrm{i02} .257$
Ciptaan disebarluaskan di bawah

Lisensi Creative Commons Atribusi-

NonKomersial-BerbagiSerupa 4.0

Internasional memperkuat kesehatan individu dan keluarga. Keterbatasan yang dialami oleh pasien post operasi menyebabkan pasien tidak mampu melakukan aktivitas dengan sendiri dan membutuhkan bantuan orang lain untuk memenuhi kebutuhannya. Keluarga adalah sebuahh unit terkecil dari masyarakat yang terdiri atas kepala keluarga dan beberapa orang yang berkumpul dan tinggal disuatu tempat dibawah suatu atap dalam keadaan saling ketergantungan. Peranan keluarga menggambarkan perilaku interpersonal, sifat, kegiatan yang berhubungan dengan individu dalam posisi dan situasi tertentu (Mubarak, W \& Chayatin, 2009). Pasangan atau suami atau keluarga dapat dilibatkan dalam sesi pengajaran atau penjelasan tentang mobilisasi dini untuk pemulihan pasangannya (Bobak \& Lowdermilk, 2012).

Berdasarkan permasalahan di atas, maka penulis tertarik mengadakan penelitian guna mengetahui "Hubungan Antara Dukungan Keluarga Terhadap
Motivasi Mobilisasi Dini Pada Ibu Post Seksio sesarea di RSUD 45 Kuningan.

\section{Metode}

Jenis penelitian analitik dengan rancangan cross sectional. Populasi dalam penelitian ini adalah seluruh ibu post seksio sesarea di RSUD 45 Kuningan yang berjumlah 40 responden. Teknik sampling menggunakan purpossive sampling. instrumen yang digunakan yaitu kuesioner, sifat dan sumber data yang digunakan dalam penelitian ini adalah data primer. Data primer diperoleh dari wawancara langsung melalui alat ukur kuesioner dengan responden yaitu keluarga dan ibu postpartum seksio sesarea, Analisis data yang digunakan dalam penelitian ini adalah analisis univariat dan bivariat analisis univariat menghasilkan distribusi dan persentase dari tiap variabel. Analisis bivariat untuk mengukur hubungan antara dukungan keluarga dengan motivasi mobilisasi dini pada ibu post seksio sesarea menggunakan uji Spearman Rank.

\section{Hasil}

Tabel 1 Distribusi Dukungan Keluarga pada Ibu Post Seksio Sesarea di RSUD 45 Kuningan

\begin{tabular}{ccc}
\hline Dukungan Keluarga & Frekuensi & Persentase \\
\hline Baik & 18 & 60 \\
Kurang & 12 & 40 \\
\hline Total & 30 & 100 \\
\hline
\end{tabular}


JOURNAL OF MIDWIFERY CARE:

VOL. 01 NO. 02, JUNI 2021

DOI: $10.34305 / \mathrm{jmc} . v 1 \mathrm{i02} .257$
Ciptaan disebarluaskan di bawah

Lisensi Creative Commons Atribusi-

NonKomersial-BerbagiSerupa 4.0

Internasional.
Berdasarkan tabel 1 di atas dapat diketahui bahwa dari 30 responden, sebagian besar dukungan keluarga baik sebanyak 18 (60\%) responden dan sebanyak $12(40 \%)$ responden memiliki dukungan keluarga kurang.

Tabel 2 Distribusi Motivasi Mobilisasi Dini pada Ibu Post Seksio Sesarea di RSUD 45 Kuningan

\begin{tabular}{ccc}
\hline Motivasi Mobilisasi Dini & Frekuensi & Persentase (\%) \\
\hline Termotivasi & 19 & 63.3 \\
Tidak Termotivasi & 11 & 36.7 \\
\hline Total & 30 & 100 \\
\hline
\end{tabular}

Berdasarkan tabel 2 tersebut dapat diketahui bahwa dari 30 responden, sebagian besar ibu post seksio sesarea termotivasi sebanyak $19(63,3 \%)$ responden dan sebanyak $11(36,7 \%)$ responden tidak termotivasi.

Tabel 3 Hubungan Antara Dukungan Keluarga dengan Motivasi Mobilisasi Dini pada Ibu Post Seksio Sesarea di RSUD 45 Kuningan

\begin{tabular}{|c|c|c|c|c|c|c|c|c|}
\hline \multirow{3}{*}{ Dukungan Keluarga } & \multicolumn{6}{|c|}{ Motivasi Mobilisasi Dini } & \multirow{3}{*}{$\begin{array}{l}\text { Nilai } \rho \\
\text { Value }\end{array}$} & \multirow{3}{*}{$\pi$} \\
\hline & \multicolumn{2}{|c|}{ Termotivasi } & \multicolumn{2}{|c|}{$\begin{array}{c}\text { Tidak } \\
\text { Termotivasi } \\
\end{array}$} & \multicolumn{2}{|c|}{ Total } & & \\
\hline & $\mathrm{N}$ & $\%$ & $\mathrm{n}$ & $\%$ & $\mathrm{n}$ & $\%$ & & \\
\hline Kurang & 4 & 33,3 & 8 & 66.7 & 12 & 100 & \multirow{2}{*}{0.004} & \multirow{2}{*}{0.508} \\
\hline Baik & 15 & 83,3 & 3 & 16.7 & 18 & 100 & & \\
\hline
\end{tabular}

Berdasarkan tabel 3 di atas menunjukan bahwa dari 18 ibu post seksio sesarea yang mendapat dukungan keluarga baik $83.3 \%$ termotivasi untuk melakukan mobilisasi dini dan $16.7 \%$ tidak termotivasi untuk melakukan mobilisasi dini. Dari 12 ibu post seksio sesarea yang memiliki dukungan keluarga kurang 33.3\% termotivasi untuk melakukan mobilisasi dini dan $66.7 \%$ tidak termotivasi untuk melakukan mobilisasi dini.
Hasil uji statistik dengan menggunakan uji Spearman Rank diketahui koefisien korelasi 0.004 ( $\rho$ value $<0.05)$ dengan tingkat signifikansi $\pi=0.508$ membuktikan bahwa ada hubungan positif dan signifikan antara dukungan keluarga dengan motivasi mobilisasi dini pada ibu post seksio sesarea dengan korelasi sedang. 
JOURNAL OF MIDWIFERY CARE:

VOL. 01 NO. 02, JUNI 2021

DOI: $10.34305 / \mathrm{jmc} . v 1 \mathrm{i02} .257$
Ciptaan disebarluaskan di bawah

Lisensi Creative Commons Atribusi-

NonKomersial-BerbagiSerupa 4.0

Internasional.

\section{Pembahasan}

\section{Analisis Univariat}

Penelitian ini menegaskan bahwa dukungan keluarga terhadap motivasi mobilisasi pada ibu post seksio sesarea dalam kategori baik. Hal ini selaras dengan hasil penelitian Kurniawati \& Widaryati, (2013) dengan judul hubungan dukungan keluarga dengan pelaksanaan mobilisasi pada pasien pasca operasi appendicitis, hasil penelitian sebagian besar dukungan keluarga memiliki dukungan yang sedang dan tinggi dalam pelaksanaan mobilisasi. salah satu faktor yang mempengaruhi sikap ibu dalam memotivasi ibu untuk melakukan mobilisasi dini setelah operasi sesar adalah dukungan keluarga. Menurut Setiadi, (2008) bahwa dukungan keluarga membuat keluarga mampu menggunakan berbagai kepandaian dan akal sebagai akibatnya, hal ini dapat meningkatkan kesehatan pasien salah satunya untuk melakukan mobilisasi.

Support system keluarga atau dukungan keluarga yang merupakan bagian dari dukungan sosial mempunyai pengaruh terhadap kesehatan. Jika keluarga bahkan lingkungan kita merasa mendukung segala sesuatu dapat menjadi lebih mudah pada waktu menjalani kejadian-kejadian yang menegangkan. Banyaknya pasien post seksio sesarea yang dirawat di Ruang Nifas
RSUD 45 Kuningan yang mendapat dukungan keluarga dalam kategori baik menunjukkan masih kuatnya ikatan emosional antara pasien dan keluarga.

Berdasarkan hasil penelitian menunjukkan bahwa $63.3 \%$ pasien post seksio sesarea di Ruang Nifas RSUD 45 Kuningan, memiliki motivasi untuk melakukan mobilisasi dini. Sejalan dengan penelitian yang dilakukan oleh Novitasari, (2011) dengan judul Hubungan motivasi dengan pelaksanaan mobilisasi dini pasca operasi sectio caesarea. Dikatakan bahwa adanya hubungan yang sangat bermakna antara motivasi dengan pelaksanaan mobilisasi pasca operasi sectio caesarea. Banyak usaha yang diperlukan untuk memotivasi ibu melakukan mobilisasi dini, bimbingan dan dukungan secara langsung sangat dibutuhkan untuk pelaksanaan mobilisasi dini.

Menurut Stanford ada 3 hal yang membuat orang termotivasi yaitu antara hubungan, dorongan dengan tujuan. Kebutuhan akan muncul karena adanya sesuatu yang kurang dirasakan oleh seseorang baik fisiologis maupun psikologis. Sedangkan dorongan adalah arahan untuk memenuhi kebutuhan dan tujuan akhir dari siklus motivasi. Motivasi yang diberikan merupakan rangsangan, 
JOURNAL OF MIDWIFERY CARE:

VOL. 01 NO. 02, JUNI 2021

DOI: $10.34305 / \mathrm{jmc} . v 1 \mathrm{i02} .257$

dorongan atau penggerak terjadinya suatu tingkah laku dalam mencapai suatu tujuan (Chlarin Horhoruw et al., 2015). Untuk berperilaku sehat, diperlukan pengetahuan yang tepat, motivasi dan keterampilan untuk berperilaku. Karena pada dasarnya manusia tidak menyukai keadaan yang tidak seimbang, maka ia berusaha membuat seimbang dengan mencari pengetahuan baru yang sejalan dengan perilakunya atau mengubah perilakunya agar sejalan dengan pengetahuan (Notoatmodjo, 2010).

\section{Analisis Bivariat}

Dari hasil uji Spearman Rank diketahui nilai $\rho 0.004$ ( $\rho$ value $<0.05)$ dengan tingkat korelasi $\pi=0.508$ membuktikan bahwa ada hubungan positif dan signifikan antara dukungan keluarga dengan motivasi mobilisasi dini pada ibu post seksio sesarea. Hasil penelitian ini didukung oleh (Sari, Arum, 2015) dalam penelitiannya yang berjudul hubungan dukungan keluarga dengan mobilisasi dini pada ibu nifas di RSU Dr. Wahidin Sudiro Husodo. Dengan menggunakan uji statistik Chi-Square didapatkan hasil Asymp.Sig = $0,002<0,05$, maka dapat disimpulkan bahwa Ho ditolak artinya terdapat hubungan yang signifikan antara dukungan keluarga dan mobilisasi pada ibu nifas.
Ciptaan disebarluaskan di bawah

Lisensi Creative Commons Atribusi-

NonKomersial-BerbagiSerupa 4.0

Internasional.
Kesimpulan penelitian adalah semakin besar dukungan keluarga maka semakin besar pula ibu nifas yang melakukan mobilisasi dini dan sebaliknya semakin kurang dukungan keluarga akan semakin kurang pula pelaksanaan mobilisasinya.

Setiap perubahan perilaku seseorang dipengaruhi oleh berbagai faktor yang dapat merubah perilaku individu itu baik perubahan yang bermanfaat bagi dirinya maupun tidak. Pada pasien post operasi biasa takut untuk melakukan mobilisasi karena cemas dengan bekas sayatan akan terlepas dan nyeri bekas operasi sehingga kekhawatiran tersebut menghalangi motivasi yang berasal dari dalam diri maupun dari luar individu. Responden yang tidak termotivasi tetapi dapat melakukan mobilisasi dapat juga dipengaruhi oleh pengalaman dan kebiasaan. Individu yang sudah pernah mengalami proses operasi sebelumnya lebih tahu menentukan mana yang baik untuk dirinya tanpa memerlukan stimulus atau motivasi dari luar atau eksternal Chlarin Horhoruw et al.,(2015).

\section{Kesimpulan}

Berdasarkan hasil penelitian dapat disimpulkan bahwa sebagian besar dukungan keluarga baik sebanyak 18 orang (60\%), Sebagian besar ibu post seksio 
JOURNAL OF MIDWIFERY CARE:

VOL. 01 NO. 02, JUNI 2021

DOI: $10.34305 / \mathrm{jmc} . v 1 \mathrm{i} 02.257$

sesarea termotivasi untuk melakukan mobilisasi dini sebanyak 19 orang (66.7\%), Terdapat hubungan yang signifikan antara dukungan keluarga dengan motivasi mobilisasi dini pada ibu post seksio sesarea di RSUD 45 Kuningan dengan nilai $\rho$-value 0.004 .

\section{Daftar Pustaka}

Amalia, F. Y. (2020). Hubungan Dukungan Keluarga Dengan Pelaksanaan Mobilisasi Dini Pada Pasien Post Operasi Di Ruang Bedah Rsud Dr . H . Bob Bazar , SKM. Jurnal Ilmu Kesehatan Indonesia (JIKSI), 1(1), 18.

Bobak, J., \& Lowdermilk. (2012). Buku Ajar Keperawatan Maternitas Edisi 4. EGC.

Chlarin Horhoruw, M., Rompas, S., \& Joli Bidjuni, H. (2015). Hubungan Motivasi Perawat dengan Kemampuan Mobilisasi Pasien Post Operasi Sectio Caesarea Di Ruangan Melati Rs. Tk. Iii R.W. Mongisi di Manado. Ejournal Keperawatan, 3.

Dinar Listiayani, R. (2014). Perbedaan Motivasi Pasien dalam Mobilisasi Dini Ibu Post Sectio Caesarea Primipara dan Multipara di RSU PKU Muhammadiyah. Naskah Puplikasi.
Ermanto, B. (2019). Efektifitas Dukungan Suami Dalam Mobilisasi Dini Pada Ibu Post SC. Jurnal Kebidanan Antara, 2(4), 376-381.

Kurniawati, F., \& Widaryati. (2013). Hubungan Dukungan Keluarga dengan Pelaksanaan Mobilisasi pada Pasien Pasca Operasi Appendicitis Di RS PKU Muhammadiyah Yogyakarta. Naskah Publikasi.

Mubarak, W, I., \& Chayatin, N. (2009). Ilmu Keperawatan Komunita Konsep Dan Aplikasi. Salemba Medika.

Notoatmodjo. (2010). Ilmu perilaku kesehatan. Rineka Cipta.

Novitasari. (2011). Hubungan Motivasi Dengan Pelaksanaan Mobilisasi Dini Pasca Seksio Di RSU Sejati Medan.

Sari, Arum, R. (2015). HUBUNGAN DUKUNGAN KELUARGA DENGAN MOBILISASI DINI IBU NIFAS di RSU Dr.WAHIDIN SUDIRO HUSODO KABUPATEN MOJOKERTO. POLITEKNIK KESEHATAN MAJAPAHIT.

Setiadi. (2008). Konsep \& Proses Keperawatan Keluarga. Graha Ilmu.

Taylor, S. (2006). Health Psychology. McGraww Hill.

Zainuddin S, K. (2002). Masalah Kesehatan Jiwa Manula. 